\title{
Aplasia Cutis Congenita
}

National Cancer Institute

\section{Source}

National Cancer Institute. Aplasia Cutis Congenita. NCI Thesaurus. Code C98822.

Localized or widespread cong enital absence of skin. The lesions most frequently occur in the scalp, are well demarcated, may be superficial or deep, and are not associated with inflammation. 